(2) Open Access Full Text Article

\title{
Increasing resistance to quinolones: A four-year prospective study of urinary tract infection pathogens
}

This article was published in the following Dove Press journal:

International Journal of General Medicine

24 August 2009

Number of times this article has been viewed

\section{Orhiosefe Omigie \\ Lawrence Okoror \\ Patience Umolu \\ Gladys Ikuuh}

Department of Microbiology, Ambrose Alli University,

Ekpoma, Nigeria
Correspondence: Lawrence Okoror

Department of Microbiology and Biotechnology, Western Delta University, PMB I0, Oghara, Delta State, Nigeria

Tel +2347035278975

Email leokoror@gmail.com
Abstract: A four-year prospective study was carried out to determine the incidence and rate of development of resistance by common urinary tract infection (UTI) pathogens to quinolone antimicrobial agents. Results show that there is high intrinsic resistance to the quinolones among strains of Pseudomonas aeruginosa (43.4\%), Escherichia coli (26.3\%), and Proteus spp. (17.1\%). Over four years, rising rates of resistance were observed in P. aeruginosa $(14.6 \%$ increase), Staphylococcus aureus $(9.8 \%)$, and E. coli (9.7\%). The highest potency was exhibited by ciprofloxacin $(91.2 \%)$, levofloxacin $(89.2 \%)$, and moxifloxacin $(85.1 \%)$, while there were high rates of resistance to nalidixic acid (51.7\%) and pefloxacin (29.0\%). Coliforms, particularly E. $\operatorname{coli}(>45 \%)$, remain the most prevalent causative agents of UTI while females within the age range of 20-50 years were most vulnerable to UTI.

Keywords: UTI, microorganisms, antibiotics, resistance

\section{Introduction}

Urinary tract infections (UTI) could be defined as the persistent presence within the urinary tract of actively multiplying microorganisms. UTI implies both microbial colonization of the urine and invasion of the lower or upper urinary tract by microorganisms. ${ }^{1}$ It is an infection with more than 100,000 organisms per milliliters in the mid-stream urine samples. ${ }^{2}$

Urinary tract infection is the most common disease of the urinary tract and it is a major cause of morbidity in both the hospital and the community. ${ }^{3}$ The most common causes of UTI are bacteria, and less often viruses, yeasts, or other intracellular microorganisms. ${ }^{4}$ According to Bohnson, ${ }^{5}$ bacteriuria may be completely asymptomatic or remain localized in the bladder without the development of renal infection. Urine secreted by normal kidneys is sterile and remains so while it travels to the bladder, however, normal urine is known to have microbial flora and any voided urine in normal patients may therefore contain thousands of bacteria per milliliter derived from this normal flora. In order to differentiate this smaller number of microorganisms from the larger number of microorganisms commonly found in UTIs, it is essential to count the number of bacteria present in freshly collected specimens by appropriate methods. ${ }^{6}$

Therapy of infectious diseases with antimicrobial agents is very dynamic as a result of increase in bacterial resistance to most available antimicrobial agents. Hence most bacterial infections, especially hospital-acquired infections, are becoming more and more difficult to treat. Bacterial resistance has been reported to almost every antimicrobial drug available; hence this study evaluated the susceptibility pattern of 
the newer and presumed more efficient antibiotics which have been reported to be effective in the treatment of lots of ailments including UTI. ${ }^{6}$ A report on the susceptibility pattern of bacteria isolated from UTI cases to quinolones will further enhance the treatment of UTI, which has become difficult to treat due to multidrug resistance. Such multidrug resistance has become increasingly common throughout the world and has become expensive to treat. ${ }^{7}$ It therefore becomes imperative to check the potency of quinolones against some principal pathogens isolated in UTI cases. In vitro tests of the potency of antimicrobial agents provide a means of obtaining rapid and inexpensive information on the treatment of UTI. ${ }^{8,9}$

In Nigeria, UTI is prevalent among men and women, but is more common among women, especially during pregnancy. ${ }^{9}$ Unrecognized UTI in infancy and childhood may have serious long-term effects and chronic pyelonephritis may occur in adults. However, the infection occurs in all persons regardless of sex or age with particular impact on the young and the very elderly. ${ }^{10}$ Sexually active females are also more predisposed to UTI than their male counterparts. ${ }^{9,11}$ In later life, UTI is more common among men until the age of prostatic hypertrophy (above 40 years of age). ${ }^{6}$

For many years, pathogens associated with uncomplicated UTI have remained constant, with Escherichia coli identified as the etiological agent in about $75 \%-90 \%$ of infections. ${ }^{12}$ Five to $10 \%$ of uncomplicated cases are caused by Staphylococcus saprophyticus ${ }^{13}$ with Klebsiella, Proteus, Enterococcus, and Pseudomonas species seen in much smaller percentages. ${ }^{14-16}$

Etiological agents of infectious disease and their sensitivity to antimicrobial drugs used for their control have always been of interest in clinical medicine. Various studies have reported the causative bacterial agents of many cases of UTIs seen in Nigerian hospitals and their in vitro sensitivity to antimicrobial agents. ${ }^{17,18}$ One common concern amongst these reports has been the increasing resistance of pathogenic bacteria isolated from clinical specimens to antibiotics commonly used within the hospital communities. ${ }^{19}$

The World Health Organization (WHO) has called antibiotic resistance an emerging disease. ${ }^{20}$ Bacteria may be innately resistant or may acquire resistance to antibiotics. The rapid spread of bacterial resistance to antimicrobial agents has led to the search for newer and more potent drugs. However, as soon as new drugs appear, irrational use and abuse of them causes bacterial resistance. An extensive body of clinical research confirms that the fluoroquinolones are extremely effective for the treatment of UTIs ranging in severity from uncomplicated cystitis to urosepsis. ${ }^{21}$ The superiority of ciprofloxacin compared to trimethoprim/ sulfamethoxazole has also been confirmed in patients with acute pyelonephritis. ${ }^{22}$

Of the newer fluoroquinolones, only levofloxacin is approved for both upper and lower UTIs. It should be emphasized that some other quinolones may demonstrate high activity against some Gram-negative organisms, and hence may be indicated for the treatment of these organisms implicated in UTI. Based on the emerging abuse of fluoroquinolone drugs and bacterial resistance in recent times, it becomes increasingly imperative to monitor drug resistance over a period of time.

\section{Materials and methods}

\section{Sampling and ethical consideration}

Mid-stream urine samples were collected from patients attending clinics for treatment of UTI. Clinical information on the patients included pain during urination, penal and vaginal discharge, urethral and vaginal itching, foul vaginal smell, and urethral irritation. Informed consent of all the patients were obtained by the heads of the various units in all the clinics sampled. All the patients during the four years of the study agreed to participate. Other necessary data regarding the patients were obtained from the clinical register. Samples were collected randomly from different hospitals and clinics in and around the Sapele Delta State of Nigeria during the years 2001, 2002, 2003, and 2004. The sample size was determined by dividing the average number of patients visiting each clinic for UTI per year by the total number of the clinics where samples were collected.

\section{Procedure}

The urine samples were immediately cultured onto nutrient agar, McConkey agar, blood agar, chocolate agar, Mannitol salt agar, and cystine lactose electrolyte-deficient (CLED) agar plates (Oxoid Ltd., Basingstoke, UK). All the samples were cultured in duplicate and incubated both aerobically and anaerobically at $37^{\circ} \mathrm{C}$ (Weiss Gallenkamp, Loughborough, UK) for 24 hours. Bacterial count and identification were done according to the standard methods of Bergey's manual, ${ }^{23}$ Harrigan and McCane, ${ }^{24}$ and Cowan and colleagues. ${ }^{25}$

Antibiotic sensitivity tests were performed using the filter paper disc diffusion method. ${ }^{26}$ The quinolone drugs used were moxifloxacin, levofloxacin, ciprofloxacin, ofloxacin (SigmaAldrich, St. Louis, MO, USA), pefloxacin, and nalidixic acid (Fidson Healthcare Plc, Lagos, Nigeria). They were all commercially obtained (Fidson Healthcare; Sigma-Aldrich). 
The bacterial isolates were subcultured into peptone water before being used for antibiotic sensitivity tests as described by Cheesbrough. ${ }^{26}$ However, the plates with more than three different types of culture were regarded as contaminants and hence eliminated from the study. Only 15 of the samples had mixed growth of E. coli and Klebsiella spp., and 10 S. faecalis and $E$. coli. Zones of inhibition were read according to the method of Stroke and Ridway. ${ }^{27}$

An Oxford strain of S. aureus, NCTC 6571, was used as control for Gram-positive bacteria while an E. coli strain, NCTC 10418, was used as control for Gram-negative bacteria. The results were statistically analyzed using regression analysis using SPSS software (version 11; SPSS Inc., Chicago, IL, USA). The total number of bacterial isolates in each year was used as the dependent variable while the number of isolates per year was used as independent variables.

\section{Results}

A total of 1,100 patients within the age ranges of $<20,20-50$ and $>50$ years comprising of $520(32.5 \%)$ males and 739 $(67.2 \%)$ females with clinical cases of UTI were sampled (Table 1). Age distribution shows that persons aged 20-50 years frequented general practice clinics for UTI treatment more often $(822 ; 74.7 \%)$, which was followed by persons aged $<20(165 ; 15 \%)$. From the samples, a total of 1,906 pure bacterial cultures were obtained with Gram-negative bacteria being predominant (Table 2). E. coli was the highest isolate (871; 45.7\%). Other isolates were Proteus spp., Klebsiella spp., and $P$. aeruginosa. The Gram-positive bacteria isolated were relatively fewer and were mainly $S$. aureus and Streptococcus spp. However, there were 87 samples with mixed culture. Only 36 of these gave the same result after a repeated sample collection and were regarded as positive cultures. Of the total bacterial isolates, $80 \%$ grew aerobically while only $20 \%$ grew anaerobically.

The mean percentage of the isolates in all years sampled are shown in Table 3. The mean percentage of $E$. coli isolates resistant to all the quinolones used increased from $21.6 \%$ in 2001 to $24.0 \%$ in 2002 . In 2003, the mean resistance was $28.1 \%$, which rose to $68.7 \%$ in 2004 , showing a $9.7 \%$ rise in resistance of $E$. coli to quinolones from 2001 to 2004. Also, for $S$. aureus there was a steady rise in resistance from 2001 to 2004. All other organisms showed increased resistance except for Klebsiella spp., which showed a minimal decrease in resistance $(0.9 \%)$ between 2001 and 2004. For P. aeruginosa, there was a marked increase in resistance to quinolones from $35.6 \%$ to $49.8 \%$, showing a $14.2 \%$ rise in resistance. The summary of susceptibility and resistance profiles for
Table I The percentage of the incidence rate of urinary tract infection according to age and sex

\begin{tabular}{lllll}
\hline Sex & \multicolumn{4}{l}{ Prevalence within age groups $(\%)$} \\
\cline { 2 - 5 } & $<\mathbf{2 0}$ years & $\mathbf{2 0 - 5 0}$ years & $>\mathbf{5 0}$ years & Total \\
\hline Male & $100(9.1 \%)$ & $179(16.3 \%)$ & $82(7.5 \%)$ & $361(32.8 \%)$ \\
Female & $65(5.9 \%)$ & $643(58.45 \%)$ & $31(2.8 \%)$ & $739(67.2 \%)$ \\
Total & $165(15 \%)$ & $822(74.7 \%)$ & $113(10.3 \%)$ & $1100(100 \%)$ \\
\hline
\end{tabular}

all identified isolates (Table 4) shows that $P$. aeruginosa exhibited the highest resistance to all the quinolones with a mean of $43.4 \%$ resistant strains while Streptococcus spp. was most susceptible to the quinolones. Among the quinolone drugs, nalidixic acid was least efficient in preventing the growth of UTI pathogens with $51.7 \%$ of all isolates resistant, while ciprofloxacin was most potent, being able to prevent the growth of $91.2 \%$ of all the UTI pathogens tested. Statistical analysis showed that there was a relationship between isolates per year $(\mathrm{R}=1.00 ; 95 \%$ confidence interval). There was also a significant difference in all the bacteria isolates per year $(\mathrm{F}=369.404,95 \% \mathrm{CI}: \mathrm{p}=0.39)$.

\section{Discussion}

In spite of the reported efficacy of the quinolones tested in this study, some isolates were found to be resistant to some of these quinolones. However, some of the quinolones, particularly ciprofloxacin and levofloxacin proved to be of high therapeutic value. The inclusion of nutrient agar and McConkey agar in this study was because these agars are routinely used for isolation in the average Nigerian hospital laboratory, and we tried to mimic as much as possible the routine Nigerian laboratory processes. This study was also able to show that there is increase in resistance to the quinolone drugs in Nigeria and this will continue if not urgently arrested. The results obtained from the four years sampled showed increase in the number of resistant isolates over the years sampled (Table 3 ). This represents a major public

Table 2 Prevalence of bacteria isolates obtained from the studied population

\begin{tabular}{lll}
\hline Bacterial isolates & No of isolates & Percentage (\%) \\
\hline Escherichia coli & 871 & 45.7 \\
Proteus spP & 286 & 15.0 \\
Klebsiella spp & 233 & 12.3 \\
Pseudomonas aeruginosa & 219 & 11.5 \\
Staphylococcus aureus & 193 & 10.1 \\
Streptococcus spp & 102 & 5.4 \\
Total & 1906 & $100 \%$ \\
\hline
\end{tabular}


Table 3 Percentage (\%) mean of quinolone resistant bacteria isolates obtained from the studied population from $200 \mathrm{I}$ to 2004

\begin{tabular}{lllllll}
\hline S/no & Isolate & $\mathbf{2 0 0 I}$ & $\mathbf{2 0 0 2}$ & $\mathbf{2 0 0 3}$ & $\mathbf{2 0 0 4}$ & $\begin{array}{l}\text { Difference in resistance } \\
\text { level from 200 I-2004 }\end{array}$ \\
\hline 1 & Escherichia coli & 21.6 & 24.0 & 28.1 & 31.3 & $9.7 \%$ Increase \\
2 & Proteus spp & 12.4 & 16.7 & 18.5 & 21.2 & $8.8 \%$ Increase \\
3 & Klebsiella spp & 11.3 & 12.0 & 11.2 & 10.4 & $0.9 \%$ Decrease \\
4 & Pseudomonas aeruginosa & 35.6 & 40.1 & 47.8 & 49.8 & $14.2 \%$ Increase \\
5 & Staphylococcus aureus & 5.5 & 8.2 & 12.7 & 15.3 & $9.8 \%$ Increase \\
6 & Streptococcus faecalis & 4.5 & 4.9 & 5.2 & 5.1 & $0.8 \%$ Increase \\
\hline
\end{tabular}

health problem that requires drastic action for it to be properly controlled as earlier reported by Ozerek and Roa. ${ }^{20}$ This study also reveals that $P$. aeruginosa, though isolated in fewer numbers, is gradually taking over as a major public health problem since this bacteria presents the highest resistance of all the bacteria isolated in this part of Nigeria. There have also been other studies which show the high drug resistance of $P$. aeruginosa in Nigeria $^{19}$ (Table 4) as well as showing the most rapid rise in resistance (Table 3 ). This does not undermine $E$. coli as the most prevalent bacteria in UTI as earlier reported by Orenstein and Wong ${ }^{28}$ and Lutters and colleagues, ${ }^{29}$ who reported that the UTI may be endogenous or exogenous. S. aureus was the most prevalent Grampositive bacteria isolated with a mean percentage of $10.1 \%$ (Table 2). The advantage of this study is that it looked at the rate of increase of bacteria drug-resistant to quinolones, which are a group of very effective drugs compared with earlier studies which only showed that organisms were drug-resistant ${ }^{22}$ but did not discuss the rates of increase.
Our study shows that resistance to quinolones continues to increase. If urgent measures are not taken to arrest the situation, we may see the return of the era of the search for new drugs to fight bacterial infections.

Age group distribution showed that UTI was high among the group aged $<20$, which continued into the group aged 20-50 (Table 1), probably because of the high sexual activity within this age group. More females were affected with UTI than their male counterparts (Table 1). This has been attributed to the shortness of the female urethra and the closeness of the vagina to the perianal region of the urethral meatus in females, and also due to the antibacterial activity of the prostatic fluid in males and the relative longer length of the male urethra., ${ }^{9,11,30}$

In summary, the susceptibility and resistance profiles of all isolates in this study have shown that ciprofloxacin and levofloxacin possess the highest efficacy among the quinolones while nalidixic acid is least therapeutic. Despite this efficacy, there was a general increase in the resistance pattern of isolates to all the quinolones used in this study. This was

Table 4 Summary of results of sensitivity/resistance profiles of all identified bacterial isolates to the quinolones

\begin{tabular}{|c|c|c|c|c|c|c|c|c|}
\hline \multirow{2}{*}{$\begin{array}{l}\text { Bacterial } \\
\text { isolates }\end{array}$} & \multirow{2}{*}{$\begin{array}{l}\text { Sensitivity } \\
\text { profiles }\end{array}$} & \multicolumn{6}{|c|}{ Number and percentage (\%) of isolates sensitive or resistant to quinolones } & \multirow[t]{2}{*}{ Mean } \\
\hline & & Moxi & Levo & Cipro & Oflo & Peflo & Nal.A. & \\
\hline Escherichia coli & $\mathbf{R}$ & $125(14.4)$ & $62(7.1)$ & $122(14.0)$ & $249(28.6)$ & $311(35.7)$ & $503(57.7)$ & $229(26.3)$ \\
\hline$(87 I)$ & $\mathbf{S}$ & $746(85.6)$ & $809(92.9)$ & $749(86.0)$ & $622(71.4)$ & $560(64.3)$ & $368(42.3)$ & $642(73.7)$ \\
\hline Proteus spp. & $\mathbf{R}$ & $12(4.3)$ & I I (3.7) & 37 (12.9) & $36(12.6)$ & 7I (24.8) & $126(44.2)$ & $49(17.1)$ \\
\hline (286) & $\mathbf{S}$ & $274(95.7)$ & $275(96.3)$ & $249(87.1)$ & $250(87.4)$ & $215(75.2)$ & $160(55.8)$ & $237(82.9)$ \\
\hline Klebsiella spp. & $\mathbf{R}$ & $18(7.6)$ & $12(4.9)$ & $4(1.6)$ & $22(9.2)$ & $20(8.5)$ & $78(33.3)$ & $26(11.1)$ \\
\hline (235) & $\mathbf{S}$ & $217(92.4)$ & $223(95.1)$ & 231 (98.4) & $213(90.8)$ & $215(91.5)$ & $157(56.7)$ & 209 (88.9) \\
\hline Pseudomonas & $\mathbf{R}$ & $127(58.2)$ & $119(54.4)$ & $2(0.9)$ & $23(10.5)$ & $126(57.5)$ & $173(79.1)$ & $95(43.4)$ \\
\hline aeruginosa (219) & $\mathbf{S}$ & $92(4 \mid .8)$ & $100(45.6)$ & $217(99.1)$ & $196(89.5)$ & $93(42.5)$ & $46(20.9)$ & $124(56.6)$ \\
\hline Staphylococcus & $\mathbf{R}$ & $\mathrm{I}(0.5)$ & $>I(0.7)$ & $<\mathrm{I}(0.3)$ & II (5.5) & $17(9)$ & $88(45.5)$ & $20(10.4)$ \\
\hline aureus (193) & $\mathbf{S}$ & $192(99.5)$ & $192(99.3)$ & $192(99.7)$ & I $82(94.5)$ & $176(9 \mid)$ & & $173(89.6)$ \\
\hline Streptococcus spp. & $\mathbf{R}$ & $\mathrm{I}(\mathrm{I} .2)$ & I (I.0) & I (I.I) & $4(3.6)$ & $7(7.1)$ & $17(16.4)$ & $5(4.9)$ \\
\hline$(102)$ & $\mathbf{S}$ & I0I (98.8) & I0I (99.0) & I0I (99.9) & $98(96.4)$ & $95(92.9)$ & & \\
\hline \multirow[t]{2}{*}{ Total (1906) } & $\mathbf{R}$ & $284(14.9)$ & $206(10.8)$ & $167(8.8)$ & 345 (18.1) & $552(29.0)$ & 985 (5I.7) & $423(22.2)$ \\
\hline & $\mathbf{S}$ & $1622(85.1)$ & 1700 (89.2) & 1739 (91.2) & $|56|$ (8I.9) & 1354 (71.0) & 92 I (48.3) & I 483 (77.8) \\
\hline
\end{tabular}

Abbreviations: Cipro, ciprofloxacin; Levo, levofloxacin; Moxi, moxifloxacin; Nal.A., nalidixic acid; Oflo, ofloxacin; Peflo, pefloxacin; R, resistant; S, sensitive. 
further confirmed by SPSS statistical analysis. However, in the course of treatment, cost, and side effects must also be considered especially concerning the low-income earners as high costs might discourage them from visiting clinics for proper examination and treatment. Drug abuse, which is a major source of multidrug resistance, must be discouraged and there should be continuous education of the general public on the need for rational use of drugs, particularly antimicrobial drugs. However, this is the first study of its type in Nigeria. The advantage of this study is that clinicians now know that some bacteria are becoming resistant to quinolones, which used to be the most valued drugs in this part of the world. This study also states the importance of carrying out sensitivity tests prior to treatment against the use of empirical treatment currently in practice in this locality.

\section{Acknowledgments}

In loving memory of my dear friend and colleague who inspired this research and supervised the laboratory work, Mr Orhionsefe Omigie. May his gentle soul rest in peace. The authors report no conflicts of interest in this work.

\section{References}

1. Reid G, Sobel JD. Bacterial adherence in the pathogenesis of urinary tract infection: a review. Rev Infect Dis. 1987;9:470-487.

2. Macleod J, Edward C, Bouchier I. Principles and Practice of Medicine. 15th edition. London, UK: English Language Book Society/Churchill Livingstone; 1984. p. 382-395.

3. Hannan M, Cormican M, Flynn J. A comparison of antimicrobial sensitivities of urinary pathogens for the years 1980 and 1990. Ir J Med Sci. 1993;162:499-501.

4. Cattell WR. Urinary tract infections in adults. Postgrad Med J. 1985;61:907-913.

5. Bohnson RR. Urosepsis. Urol Clin North Am. 1986;13:627-635.

6. Schroeder SA, Krupp JA, Tierney LM, Mephee SJ. Current Medical Diagnosis and Treatment. New York, NY: Appleton and Lange; 1990. p. 622-628.

7. Neild GH. Renal medicine: Urinary tract infection. Africa Health. 2005;27(2):13-18.

8. Oakes RR, Badger R, Grove DI. Comparison of direct and standardized testing of infected urine for antimicrobial susceptibilities by disk diffusion. J Clin Microbiol. 1994;32:40-45.

9. Johnson JR, Tiu FS, Stamm WE. Direct antimicrobial susceptibility testing for acute urinary tract infections in women. J Clin Microbiol. 1995;33:2316-2323.
10. Rubin RH, Tolkoff RNE, Contran RS. Urinary tract infections: pyelonephritis and reflux nephropathy. Pediatrics. 1986;83:1085-1141.

11. Wiswell TE, Smith FR, Bass JW. Decreased incidence of urinary tract infections in circumcised male infants. Pediatrics. 1985;75:901-903.

12. Hooton TM, Stamm WE. Diagnosis and treatment of uncomplicated urinary tract infections. Infect Dis Clin North Am. 1997;11:551-581.

13. Gupta K, Scholes D, Stamm WE. Increasing prevalence of antimicrobial resistance among uropathogens causing acute uncomplicated cystitis in women. JAMA. 1999;281:736-738.

14. Kahlmeter G. The ECO* SENS project: A prospective, multinational, multicentre epidemiology survey of the prevalence and antimicrobial susceptibility of urinary tract pathogens - interim report. J Antimicrob Chemother. 2001;46(Suppl A):15-22.

15. Gupta K. Antimicrobial resistance among uropathogens that cause community-acquired urinary tract infection in women: a nationwide analysis. Clin Infect Dis. 2001;33:89-94.

16. Wright SW, Wrenn KD, Haynes M, Haas DW. Prevalence and risk factors for multidrug resistant uropathogens in ED patients. Am JEmerg Med. 2000;18:143-146.

17. Alausa KO, Montefiore D. Bacterial infections, sensitivity patterns, and chemotherapy among hospital patients in tropics. Scand J Infect Dis. 1978;10:295-299.

18. Coker AO, Ijaduola GTA, Odugbemi O. Bacterial isolates from chronic discharging ears of Nigerian Children. East Afr Med J. 1983;60:462-466.

19. Eke PI, Rotimi VO. Resistance of pathogenic bacteria to antibiotics. Afr J Med Sci. 1987;16:1-8.

20. Ozerek AE, Roa GG. Antibiotics Resistance. London, UK: Department of Microbiology, Lewishman University Hospital; 2000.

21. Ronald A. The quinolones and renal infection. Drugs. 1999;58(Suppl 2): 96-98.

22. Talan DA, Stamm WE, Hooton TM, et al. Comparison of ciprofloxacin (7 days) and trimethoprim-sulfamethoxazole (14 days) for acute uncomplicated pyelonephritis pyelonephritis in women: a randomized trial. JAMA. 2000;283:1583-1590.

23. Buchanan RE, Gibbons NE. Bergey's Manual of Determinative Bacteriology. 8th edition. Baltimore, MD: Williams \& Wilkins; 1974.

24. Harrigan WF, McCane ME. Laboratory Methods in Microbiology. New York, NY: Academic Press; 1976.

25. Cowan ST, Burrow GI, Feltham RKA, editors. Cowan and Steel's Manual for the Identification of Medical Bacteria. 3rd edition. Cambridge, UK: Cambridge University Press; 1993.

26. Cheesbrough M. Biochemical tests to identify bacteria. In: District Laboratory Practice in Tropical Countries, Part 2. Cambridge, UK: Cambridge University Press; 2000. p. 63-70.

27. Stroke E, Ridway T. Antibiotics susceptibility test. In: Bailey T, Stanley M, editors. Diagnostic Microbiology: A Laboratory Manual, 6th edition. Saint Louis, MO: CV Mosby Company; 1980. p. 31-32.

28. Orenstein R, Wong ES. Urinary tract infections in adults. Am Fam Physician. 1999;59:1225-1234, 1237.

29. Lutters M, Vogt N. Antibiotics duration for treating uncomplicated, symptomatic lower urinary tract infections in elderly women. Cochrane Database Syst Rev. 2002;(3):CD001535.

30. Lipsky BA. Urinary tract infections in men: Epidemiology, pathophysiology, diagnosis, and treatment. Ann Intern Med. 1989;110:138-150.

International Journal of General Medicine

\section{Publish your work in this journal}

The International Journal of General Medicine is an international, peer-reviewed open-access journal that focuses on general and internal medicine, pathogenesis, epidemiology, diagnosis, monitoring and treatment protocols. The journal is characterized by the rapid reporting of reviews, original research and clinical studies across all disease areas.

A key focus is the elucidation of disease processes and management protocols resulting in improved outcomes for the patient.The manuscript management system is completely online and includes a very quick and fair peer-review system. Visit http://www.dovepress.com/ testimonials.php to read real quotes from published authors. 